\title{
Geosynthetic capping of a large tailings storage facility
}

\author{
T.G. Fitton ATC Williams, Australia \\ K.D. Seddon ATC Williams, Australia
}

M.G. Alexander Peabody Energy Australia, Australia

\begin{abstract}
The capping of a large tailings storage facility using geosynthetic material and rockfill is presented as a case study. This paper focuses on a project to place a 13 metre thick capping layer over a 24 hectare, 40 metre deep in-pit coal tailings storage facility (TSF) in the Hunter Valley, in eastern Australia. The coal tailings stored in this mined out pit possess very low strength, and conventional attempts at capping have proven to be unsuccessful due to stability failures of the tailings. A geosynthetic capping design was developed, in which the entire surface of the tailings is to be covered in geosynthetic material that is anchored around the perimeter of the TSF, enabling the careful placement of layers of fill material using lightweight earthmoving equipment. Innovative methods of placement and joining of the geosynthetic material have been developed. The methods of fill placement on the weak tailings have also been innovative, with the deployment of unconventional machinery where most other earthmoving machines have been unable to work. This paper presents an overview of this project, as well as some of the details of the solutions that have been developed.
\end{abstract}

\section{Introduction}

The North East tailings dam (NE TD) is an in-pit tailings storage facility at the Wambo Coal Mine in New South Wales, Australia. This mined-out pit is approximately $1,200 \mathrm{~m}$ long, $200 \mathrm{~m}$ wide and $45 \mathrm{~m}$ deep, and it is filled with coal tailings to a depth of about $40 \mathrm{~m}$. A photograph of the TSF prior to capping works commencing is presented as Figure 1. The operator of the mine wishes to cap the tailings with a layer of waste rock totalling $13 \mathrm{~m}$ in thickness within a 20 month period as part of the rehabilitation of the site.

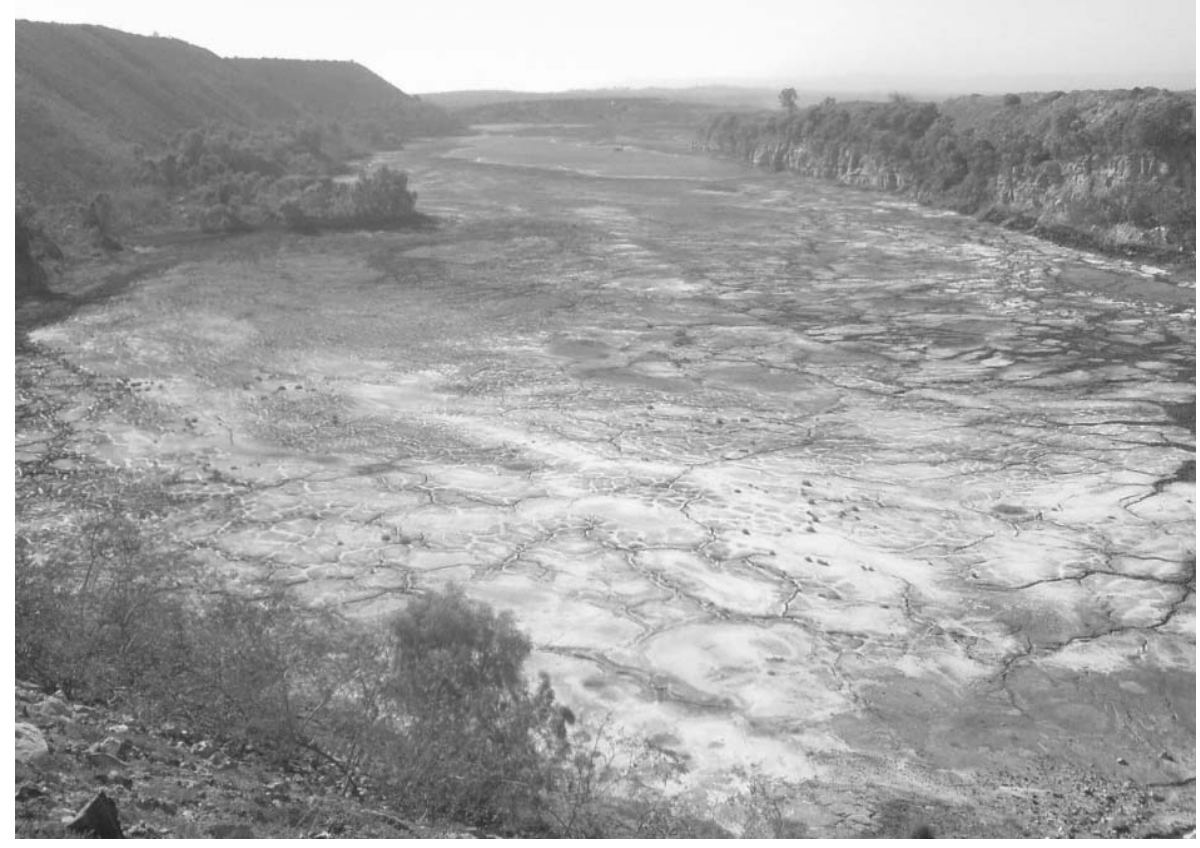

Figure 1 Wambo NE TD prior to commencement of capping operations 


\section{Tailings characteristics}

Shear vane testing was conducted in several locations on the NE TD to measure the shear strength at various depths up to $6 \mathrm{~m}$. Results of this shear vane testing are presented in Figure 2. Initially about 20\% of the tailings surface was covered in water, which prohibits the formation of a crust. The dry portion has a crust on its surface, with significantly greater shear strength than the tailings below. The crust is typically about $0.4 \mathrm{~m}$ thick, and its strength varies between 3 and $30 \mathrm{kPa}$. Directly below the crust, the tailings were measured to have shear strength values between 0 and $5 \mathrm{kPa}$.

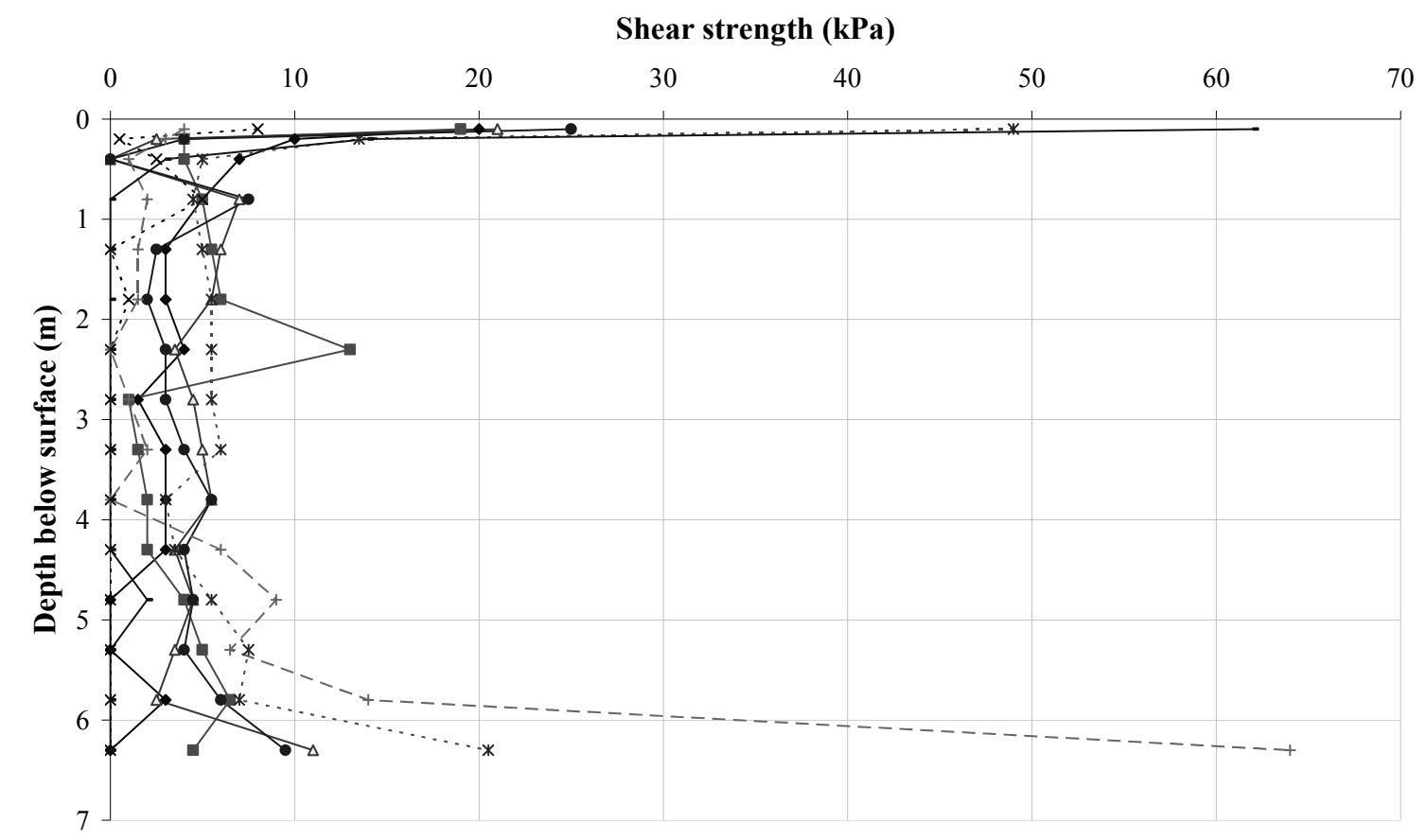

Figure 2 Wambo NE TD tailings - shear strength (measured with vane) versus depth

Laboratory testing of a sample of the Wambo NE TD tailings recovered from just below the surface crust revealed the following parameters:

$\begin{array}{ll}\text { Particle specific gravity (SG) } & 2.0 \\ \text { Atterberg Limits } & \text { PI } 109 \% \quad \text { LL } 131 \% \\ \text { Consolidation test (Rowe Cell) } & \mathrm{c}_{\mathrm{V}}=0.13 \mathrm{~m}^{2} / \mathrm{year} \text { at } 100 \mathrm{kPa}\end{array}$

PI (plasticity index); LL (liquid limit); $\mathrm{c}_{\mathrm{v}}$ (coefficient of consolidation)

The Rowe Cell test took about seven months, where most other tailings typically take about four weeks.

Moisture Content $106 \%$ (49\% solids w/w)

The tailings particles are extremely fine, with a $\mathrm{d}_{50}$ of 7 micron. Figure 3 shows a particle size distribution curve for the Wambo tailings, with a number of other coal tailings particle size distribution (PSD) curves plotted for comparison.

Under the USCS, the Wambo tailings would be classified as a High Plasticity Clay $(\mathrm{CH})$. 


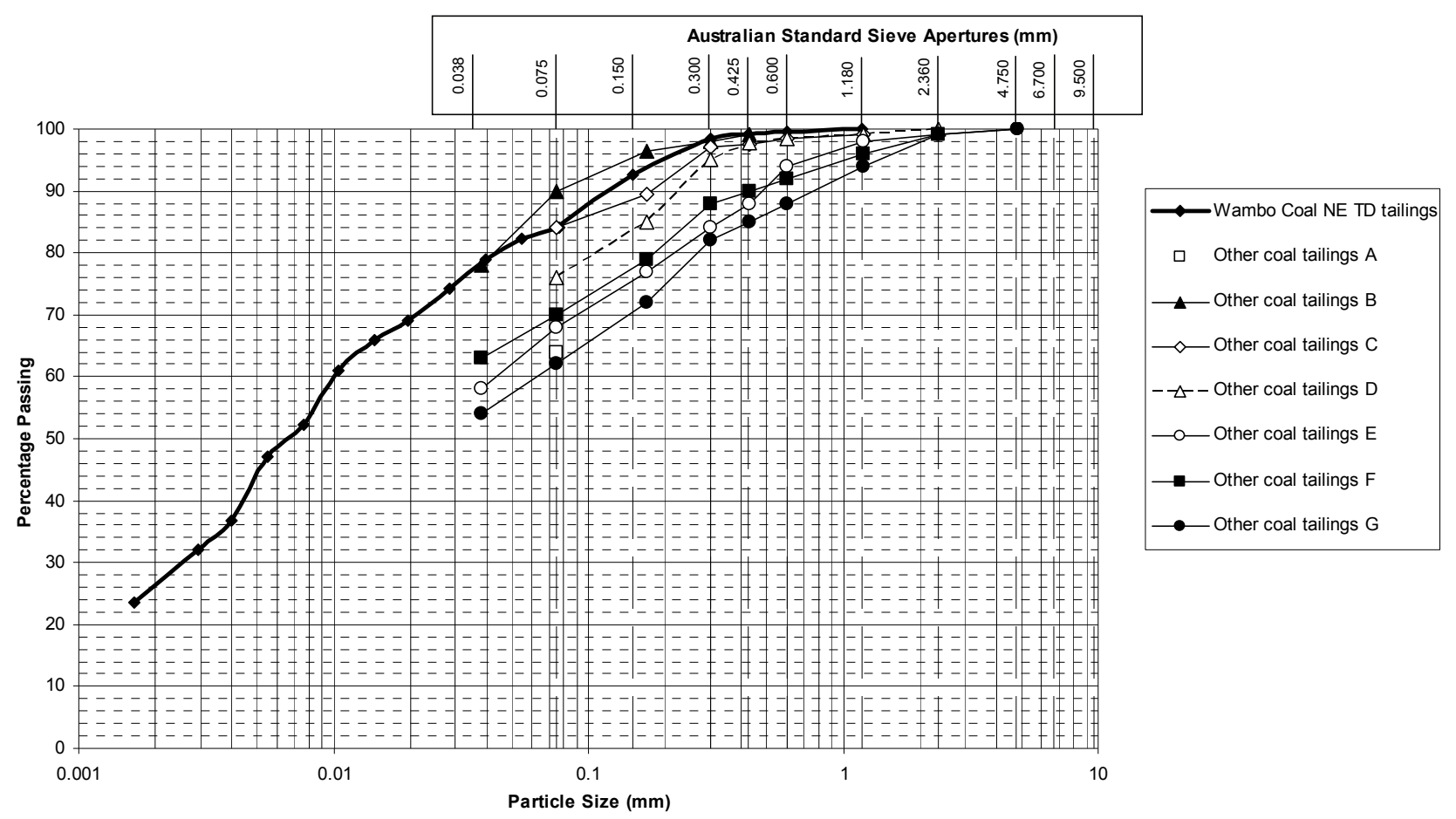

Figure 3 Wambo NE TD tailings PSD, with some other coal tailings presented for comparison

\section{Capping method selection}

Several methods were considered in an initial options study for capping the tailings in the NE TD:

- Displacement method: This involves pushing a thick layer of fill into the tailings from all sides, causing displacement of the tailings. It is often the cheapest method, but it was ruled out for this job, as it was expected that the amount of displacement would be too great, and that the safety risk would be unacceptable.

- Controlled placement of tailings: This method, with the intermittent discharge of tailings slurry to form thin layers and then allowing them to dry, was economical and safe, but it required a long time.

- Placement of modified tailings slurry (with cement added): Was ruled out because it was expected that the fine particle size distribution of the tailings slurry would not be ideal for the hydration reaction to occur. This was also expected to be quite expensive.

- Beached capping layers: This method entails the multi-point discharge of slurry with coarse particles, with the aim of creating numerous steep, well-drained deposits on the tailings surface. This method was found to be economically favourable, but more importantly, was deemed to be safe because it was expected to be achievable without any personnel or plant working on the tailings surface. However, it was not selected because of time constraints.

- Electro kinetic methods of improving the strength of the tailings were ruled out because of the access issues involved with the installation of electrodes into the tailings, as well as the relative infancy of this technology.

- Placement of capping layers with machinery was a favourable option for economic and timing reasons, but stability analyses found that the tailings would not support the necessary fill and equipment.

- Placement of capping layers with the use of geosynthetic reinforcement material was selected. The main driver for this selection was the limited amount of time available for the capping work to be 
completed. It was found that the capping could proceed with an acceptable level of safety, provided the detailed design limits were met.

\section{$4 \quad$ Capping design}

An iterative trial-and-error procedure was followed for designing the capping for the NE TD:

1. Adopt a strength profile (with respect to depth) for the tailings (see Figure 4).

2. Adopt a geosynthetic material.

3. Adopt a fill material (type and properties).

4. Adopt a fill layer thickness.

5. Adopt an earthmoving machine to spread and place the fill.

6. Undertake stability analyses (consider both global and local failure of the tailings, as shown in Figures 5 and 6).

Steps 4-6 were repeated until a practicable layer thickness and earthmoving machine type were reached for each layer.

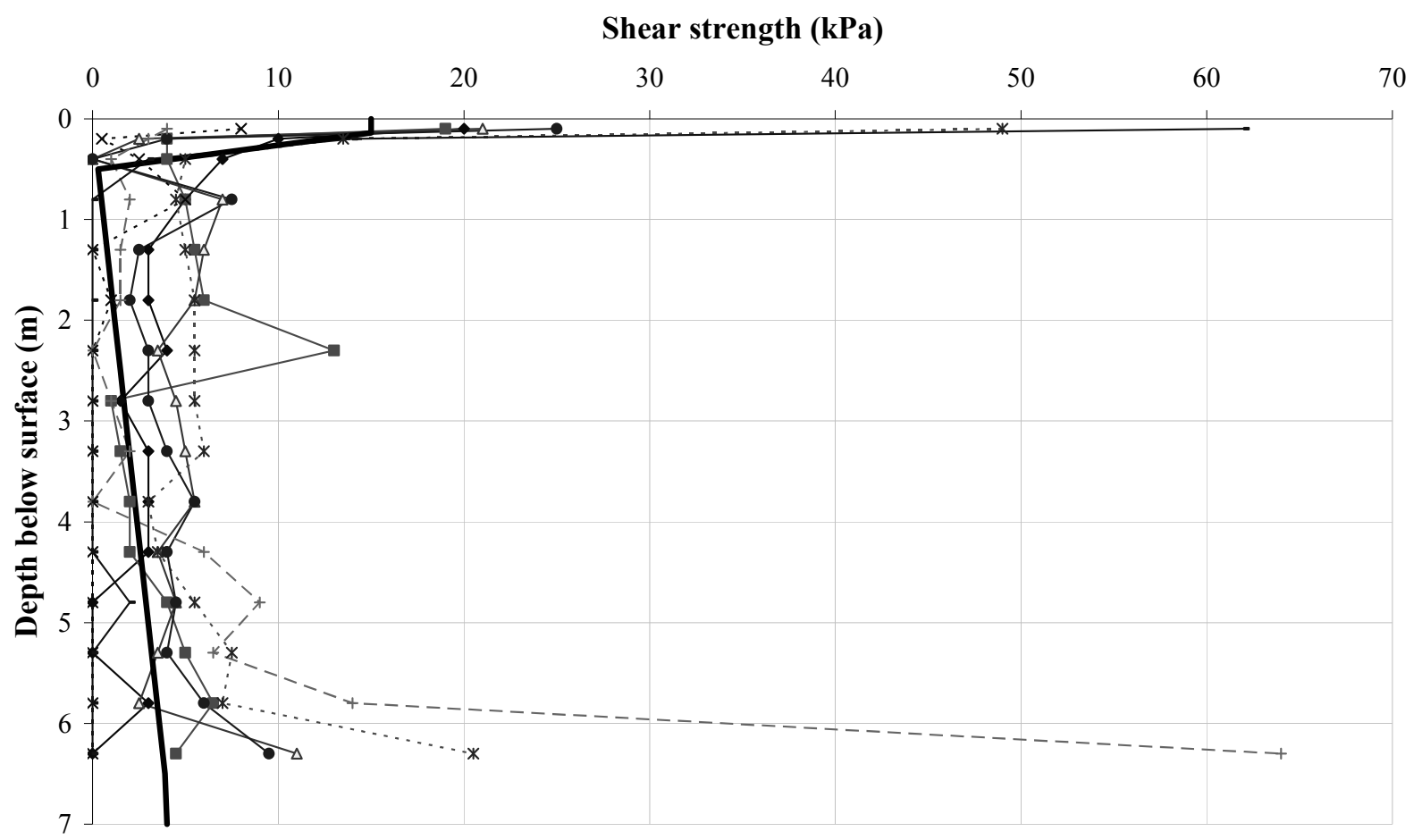

Figure 4 Wambo NE TD tailings - shear strength profile adopted for design (heavy solid line)

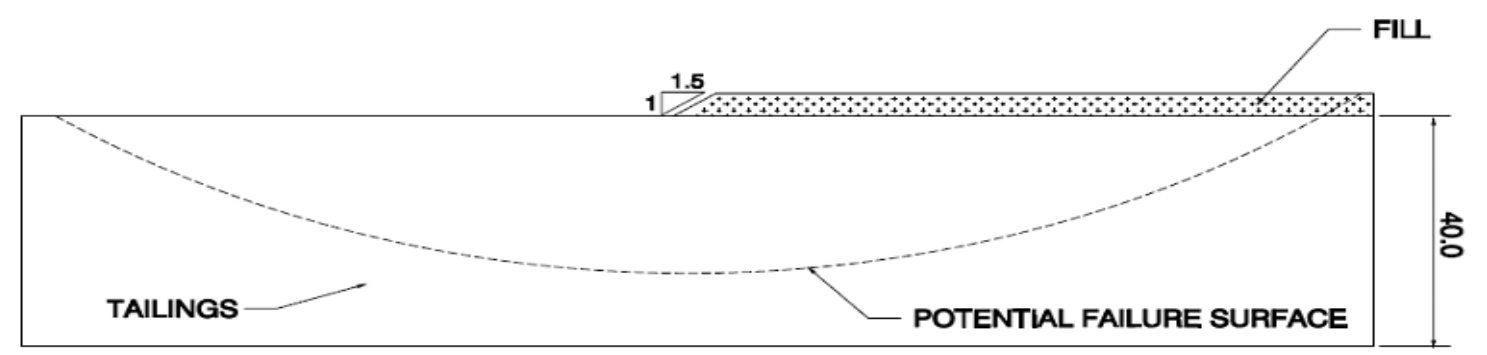

Figure 5 Stability analysis of capping on tailings - global failure 


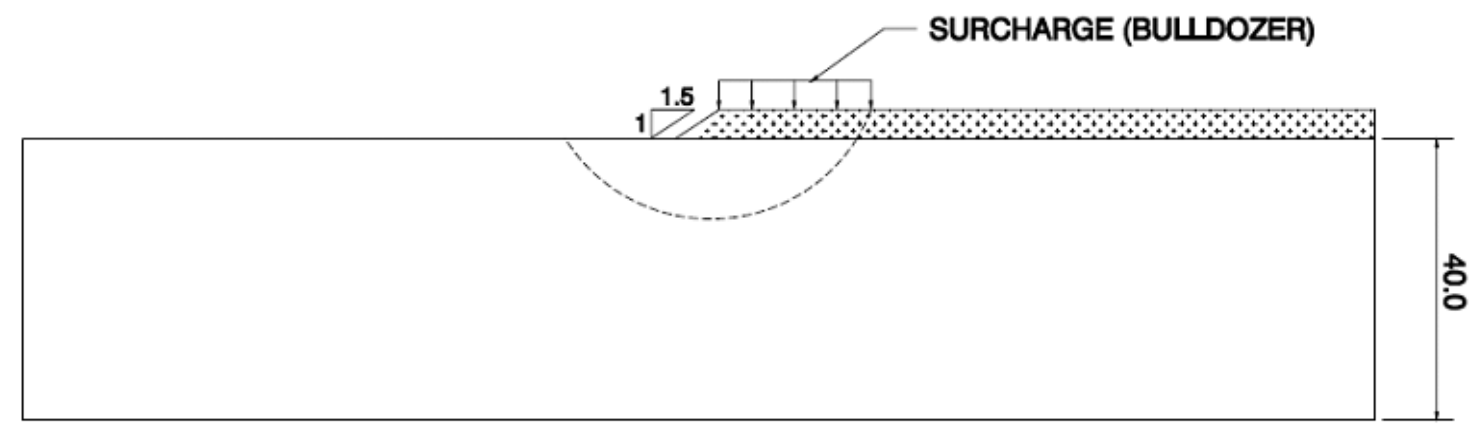

\section{Figure 6 Stability analysis of capping on tailings - local failure}

Several other important details were considered in the capping design:

- Performance of the geosynthetic (stretch, retention of fine material and fluids).

- Joining the seams of the geosynthetic.

- Anchoring of the geosynthetic.

- Allowable distances between machines.

- Offset distances from the edge of one layer to the edge of the one above it.

- Monitoring any movement of the tailings during the capping works.

A summary of the prescribed capping layer thicknesses and machine types is presented in Table 1.

Table 1 Summary of capping layers prescribed for the NE TD

\begin{tabular}{llllll}
\hline Layer & $\begin{array}{l}\text { Thickness } \\
(\mathbf{m})\end{array}$ & $\begin{array}{l}\text { Cumulative } \\
\text { Thickness }(\mathbf{m})\end{array}$ & Material & Machines & $\begin{array}{l}\text { Proximity } \\
(\mathbf{m})\end{array}$ \\
\hline 1 & 0.3 & 0.3 & Mixed reject & D2 + Marooka & 40 \\
2 & 0.3 & 0.6 & Mixed reject & D2 + Marooka & 40 \\
3 & 0.6 & 1.2 & Mixed reject & D6 LGP + 725 & 40 \\
4 & 1.0 & 2.2 & Mixed reject & D6 LGP + 725 & 20 \\
5 & 1.0 & 3.2 & Waste rock & D8 + 725 & 20 \\
6 & 1.5 & 4.7 & Waste rock & D8 +725 & 10 \\
7 & 2.0 & 6.7 & Waste rock & D11+777 & 10 \\
8 & 3.0 & 9.7 & Waste rock & D11+777 & 15 \\
9 & 3.3 & 13.0 & Waste rock & D11+777 & 20 \\
\hline
\end{tabular}

Several entries into Table 1 require some explanation:

- 'Mixed reject' is a waste product from the coal washery, which is the combination of sand fines and coarse reject waste streams. The sand fines reject contains all waste particles between 0.2 and $1.4 \mathrm{~mm}$ in diameter. The coarse reject contains particles from 1.4 to $60 \mathrm{~mm}$. The $\mathrm{SG}$ of these reject particles is around 2.3.

- 'Waste rock' is the overburden from the mining operations. Solids SG is typically 2.8.

- 'Marooka' is a tracked tip truck with a low ground pressure. 
- 'Proximity' refers to the minimum distance that must be maintained between any two machines working on a given layer.

In addition to the requirements set out in Table 1, minimum edge offset distances were prescribed to enable multiple layers to be constructed simultaneously without inducing a global failure. The minimum offset distances prescribed for the NE TD are presented in Figure 7.

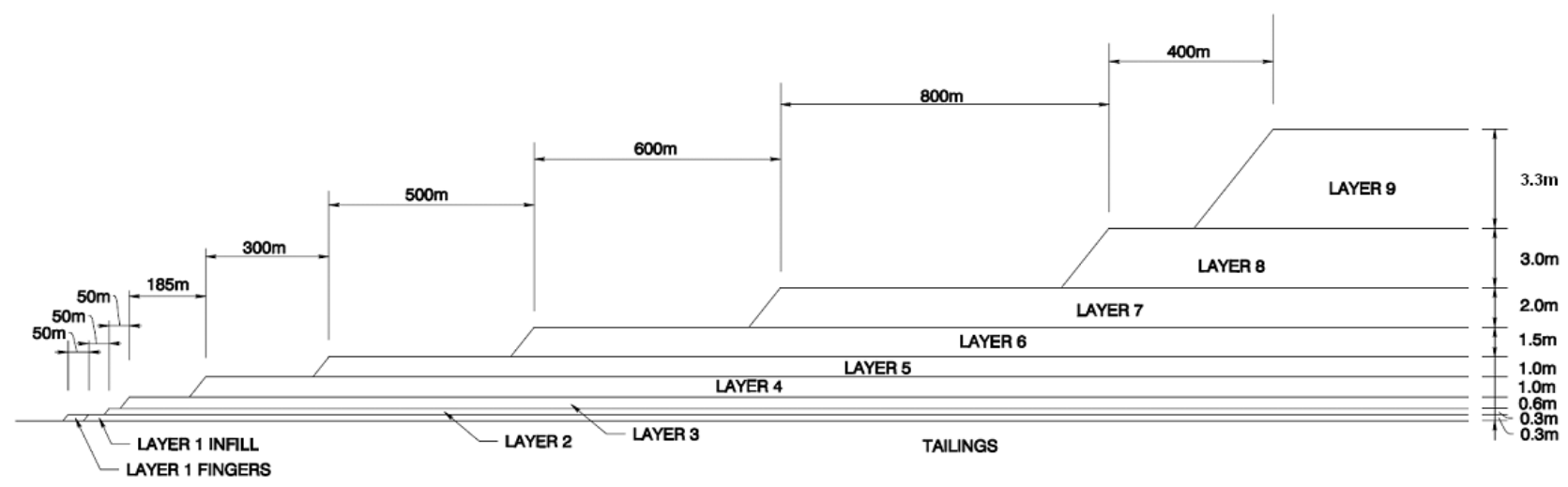

Figure 7 Illustration showing the minimum offset distances prescribed for the NE TD

Finally, a survey monitoring program was implemented, requiring a weekly survey of some 20 points on the tailings surface to detect any movements as a result of the capping works.

\section{Construction sequence and method}

The first step in the capping works was the placement of the geosynthetic material. For the final design, a two-layer system was adopted. A geogrid was selected for its strength, whilst a non-woven geofabric was placed under it to restrict the tailings from oozing up through the apertures in the grid. The grid had a primary tensile strength of $200 \mathrm{kN} / \mathrm{m}$. A special dolly was built for the task of placing the two strips of fabric simultaneously, allowing better speed of placement than laying each strip separately, and ensuring that the two strips were placed along the same line. The dolly was towed across the NE TD with a cable that was pulled from the opposite side of the tailings. This is illustrated in Figure 8.

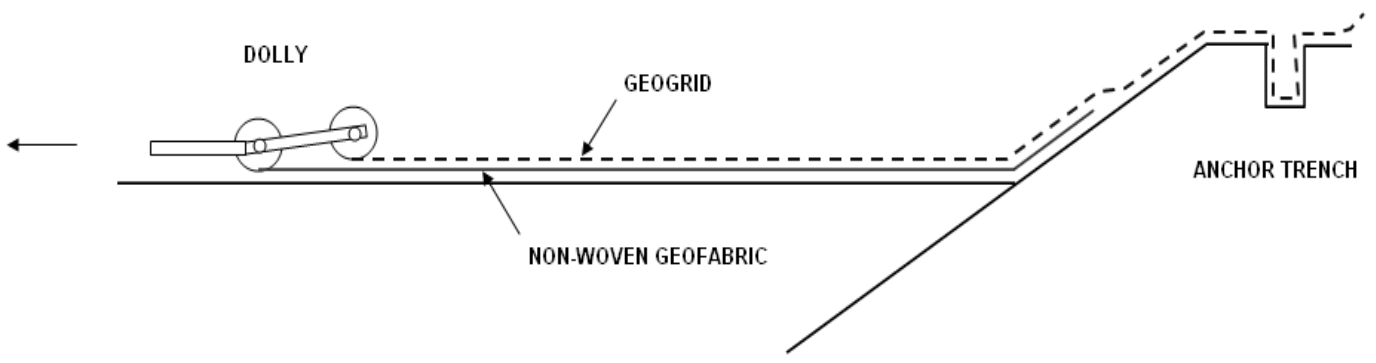

Figure 8 Placement of two strips of geosynthetic material simultaneously with a special dolly

The geosynthetic strips were placed to run across the short axis of the NE TD, typically a distance of about $200 \mathrm{~m}$. Each strip was tied to the ones beside it, using plastic cable ties. The geogrid was anchored in a backfilled trench, but the geofabric was not taken as far as the anchor trench.

The second stage in the capping works was the placement of fill on top of the geogrid. For the initial layer, this fill was specified to be placed in fingers running at a $45^{\circ}$ angle to the direction of the geogrid strips, as illustrated in Figures 9 and 10. It would have been preferable to have the fingers running perpendicular to the geogrid strips, but this was not possible because of the site configuration. This method of building fingers was based on that proposed by Broms (1987), which had been previously applied on a smaller scale at 
another site (Hashim and Murphy, 1994). There are several major benefits for placing the fill in fingers rather than simply pushing it out in a wide front. Firstly, as proposed by Broms (1987) this method distributes the weight of the fingers over the entire tailings surface, with the fingers sinking into the tailings, forcing the tailings to form mounds in between them. These mounds and troughs take up the expected elongation in the geogrid and pre-stress it, effectively spreading the load of the fingers over the whole area. Secondly, the use of fingers instead of a front minimises the tensile stresses experienced at any one point in the geogrid, since the pushing of a front across the TSF will impose a greater tensile stress in the geogrid at the leading edge of the front. Thirdly, the placement of fingers provides better anchorage along the length of the geogrid, since it minimises the potential for an unrestrained long section of geogrid to elongate. Finally, from the perspective of a global failure, the construction of fingers is equivalent to the placement of a much thinner layer across the whole surface.

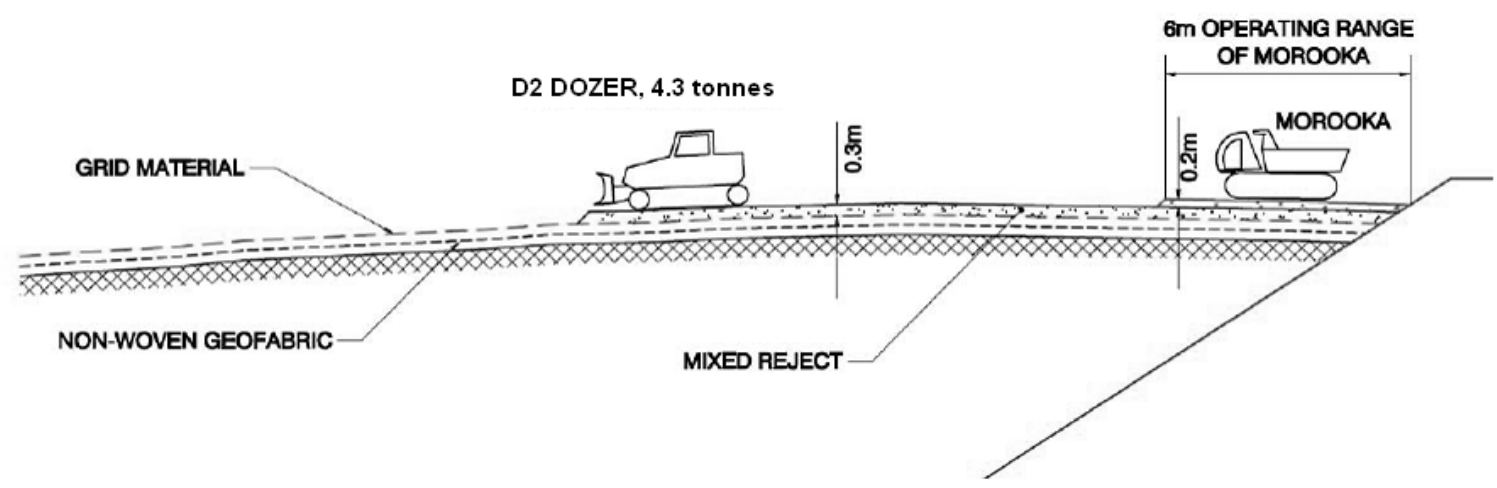

Figure 9 Placement of mixed reject (waste product from the coal washing process) in fingers

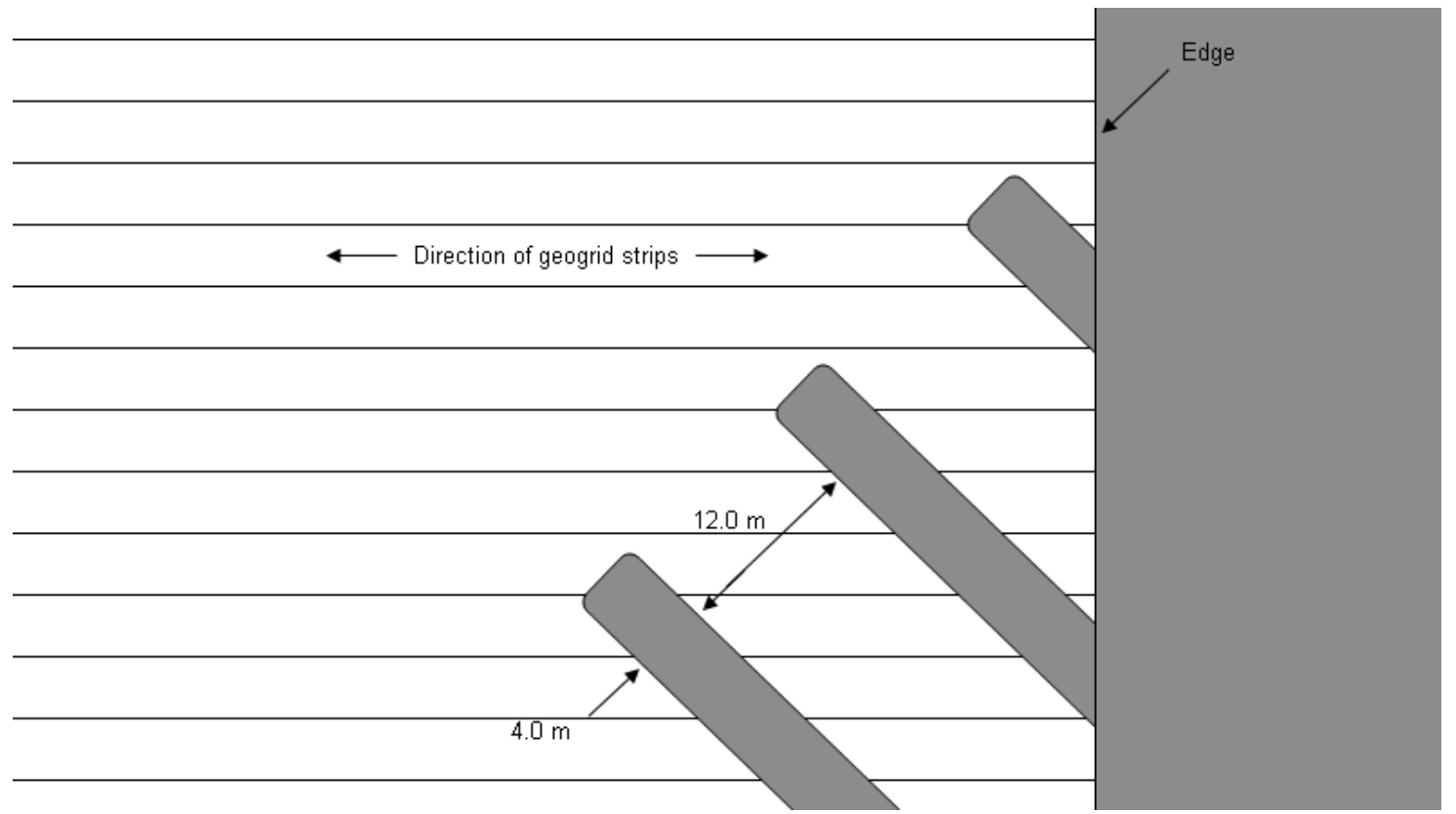

Figure 10 Plan view of the fingers

Once the fingers have been built out a minimum prescribed distance, the infill between them can be placed to the same depth as the fingers. This effectively sees the first layer of fill complete.

At the time of writing, construction is up to this point. Following is the planned placement to complete the capping project.

The second layer follows on, with a minimum set-back distance prescribed. This enables the second layer to be placed while other equipment is still placing the first layer. With each additional layer placed, the size of 
the earthmoving equipment can increase, thus increasing the rate of placement of fill. Figure 11 illustrates the design for placement of Layer 3. It is noted that limits have been set for the extent to which a truck can approach the leading edge of the layer, and different limits have also been set for the minimum allowable distance that the dozer can be from the truck.

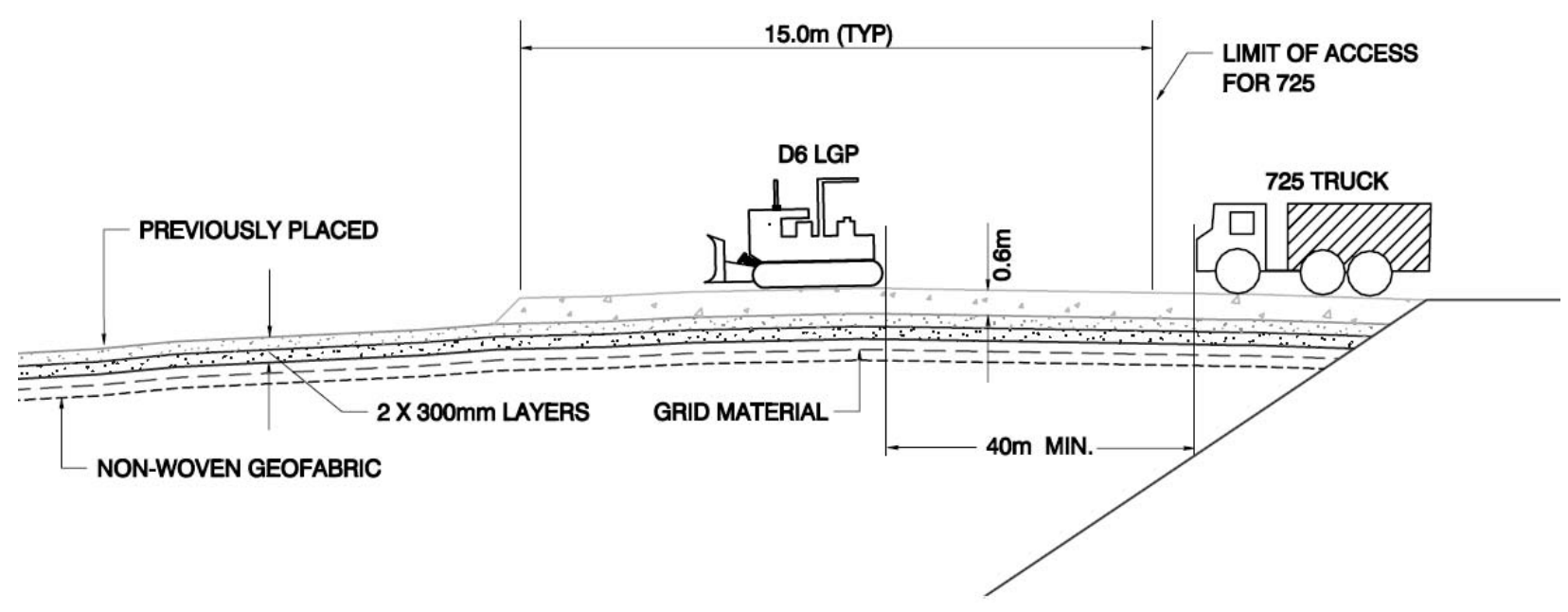

Figure 11 Placement of the third layer of fill

The sequence of layers continues as such, with the thickness of each layer getting progressively greater. Figure 12 illustrates the placement of the ninth and final layer.

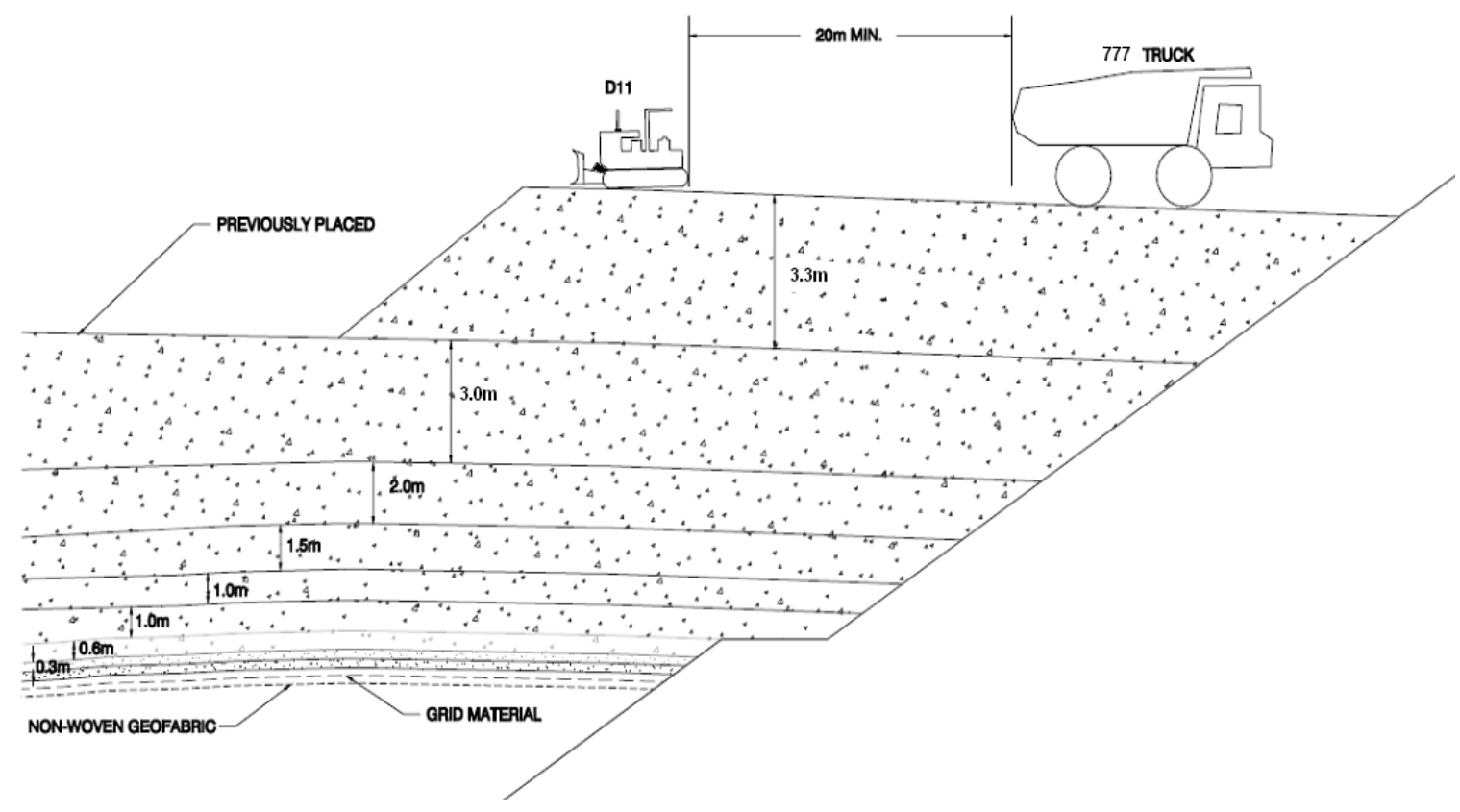

Figure 12 Placement of the ninth layer of fill

The operator of the mine chose to manage the capping construction itself, so as to maintain control of the works to ensure that the requirements of the design were met. All earthmoving equipment and other plant were externally hired on hourly rates. Figures 13 and 14 show finger placement on the NE TD. 


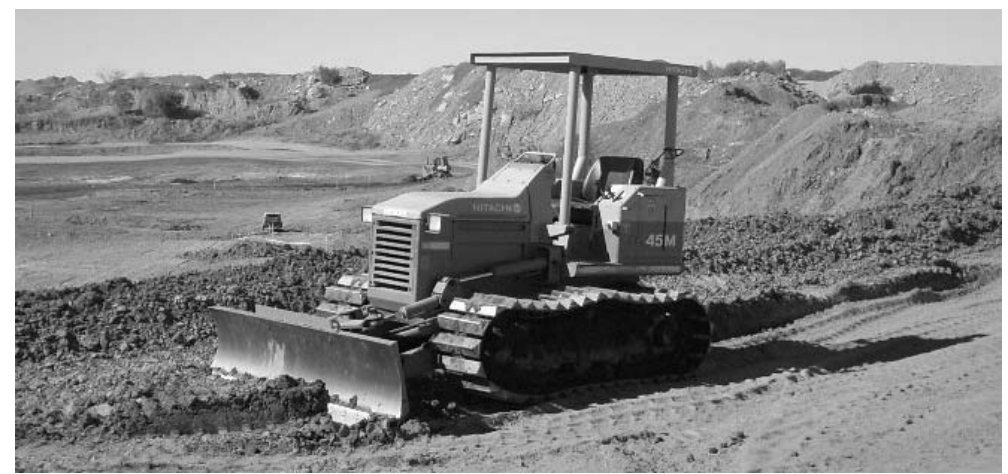

Figure 13 Photograph of a dozer equivalent to a D2, with low ground pressure tracks. This machine has been used to push mixed reject material onto the NE TD in fingers

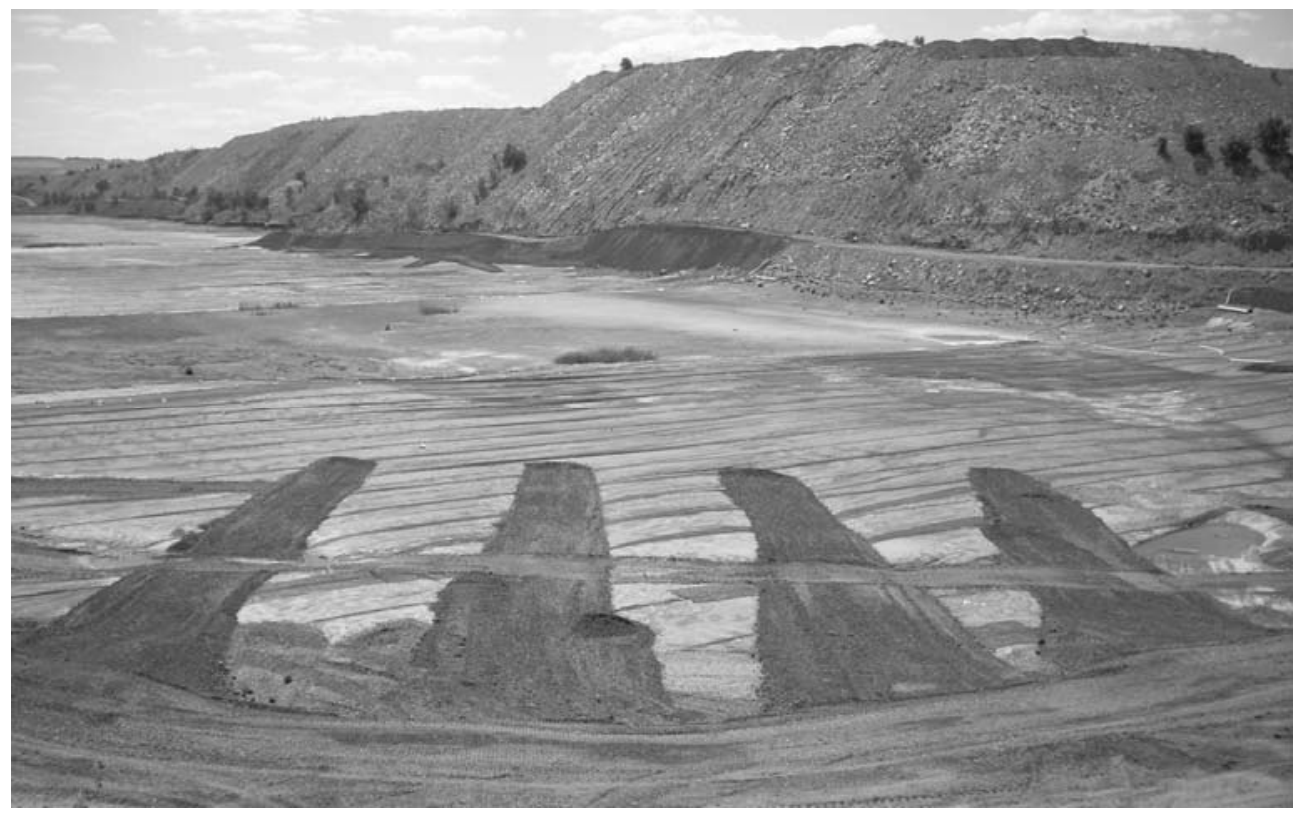

Figure 14 Photograph of several fingers on the geosynthetic material

\section{Challenges and innovations}

The capping of the Wambo NE TD presented many challenges, requiring numerous innovations to meet them.

Access to the tailings perimeter was a significant challenge. On the south side of the NE TD is an $8 \mathrm{~m}$ vertical high-wall, whilst on the north and west sides there are $50 \mathrm{~m}$ high waste dumps, with waste rock standing at its angle of repose all the way to the bottom of the pit that is now filled with tailings. These difficult perimeter conditions forced the application of several approaches to the anchoring of the geogrid, and also for the delivery of fill material to the edge of the NE TD. At the high-wall, excavators have been deployed to batter it back from above. In the areas with waste dumps sloping down to the tailings surface at their angle of repose, perimeter access tracks have been constructed on top of the edge of the tailings.

Rolling the geosynthetic strips across the tailings without placing any personnel or machinery on the tailings surface was a challenge, particularly on areas inundated with water. To meet this challenge, a dolly was built for placing the geosynthetic strips on the tailings surface (see Figures 8 and 15). This was a dispenser that could hold the geofabric and geogrid rolls, and lay them down on the tailings surface simultaneously. The rolls would be loaded into the dolly on one side of the NE TD, and a cable would be used to pull the dolly across to the other side. New geosynthetic rolls would then be loaded into the dolly on the opposite side of the NE TD, and the dolly would be pulled back across. This operation could be performed without sending 
any personnel or plant onto the uncovered tailings surface. Punts (flat-bottomed boats) were added to the dolly to make it float across the ponded water. These punts were also able to skid across the tailings in dry areas.

Joining the seams of the geogrid strips posed another challenge, as it was often submerged under shallow water. To address this problem, plastic cable ties were used to fix the seams of the geogrid. These could be installed safely and efficiently in shallow water. Three labourers were able to keep up with the pace of the geosynthetic placement. Figure 16 shows the cable tying in progress.

A conveyor slinger truck was employed on the NE TD to throw the fill material, as an alternative to pushing it out with a dozer (see Figure 17). This was helpful in places that were particularly soft.

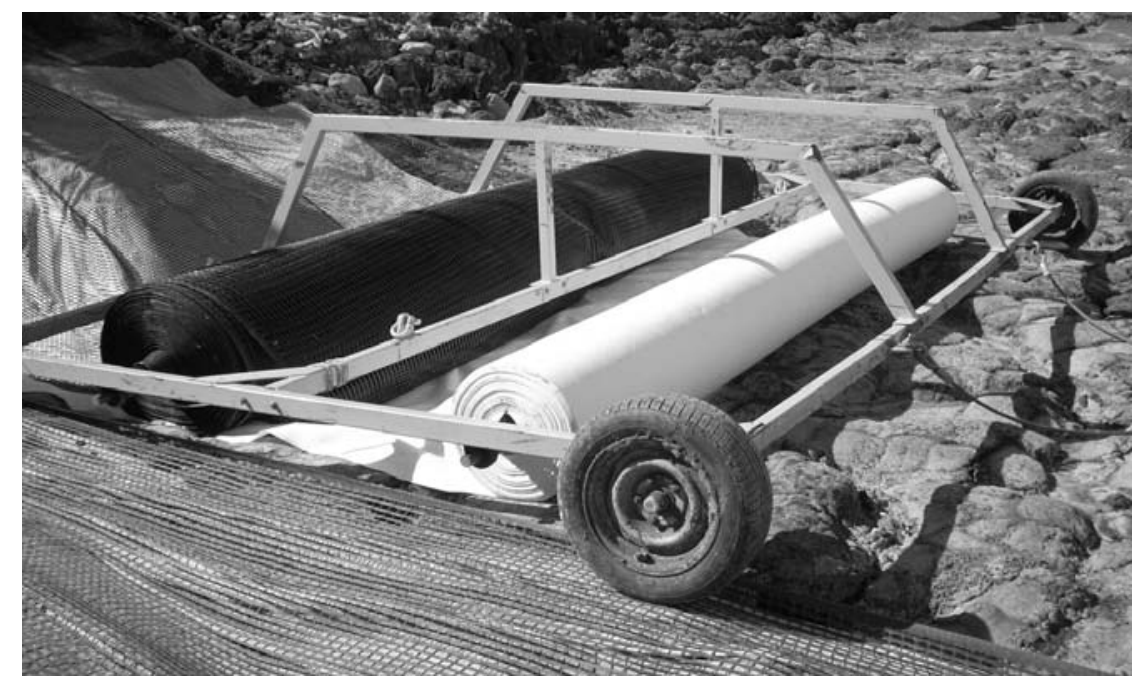

Figure 15 Photograph of dolly for placement of geosynthetic material

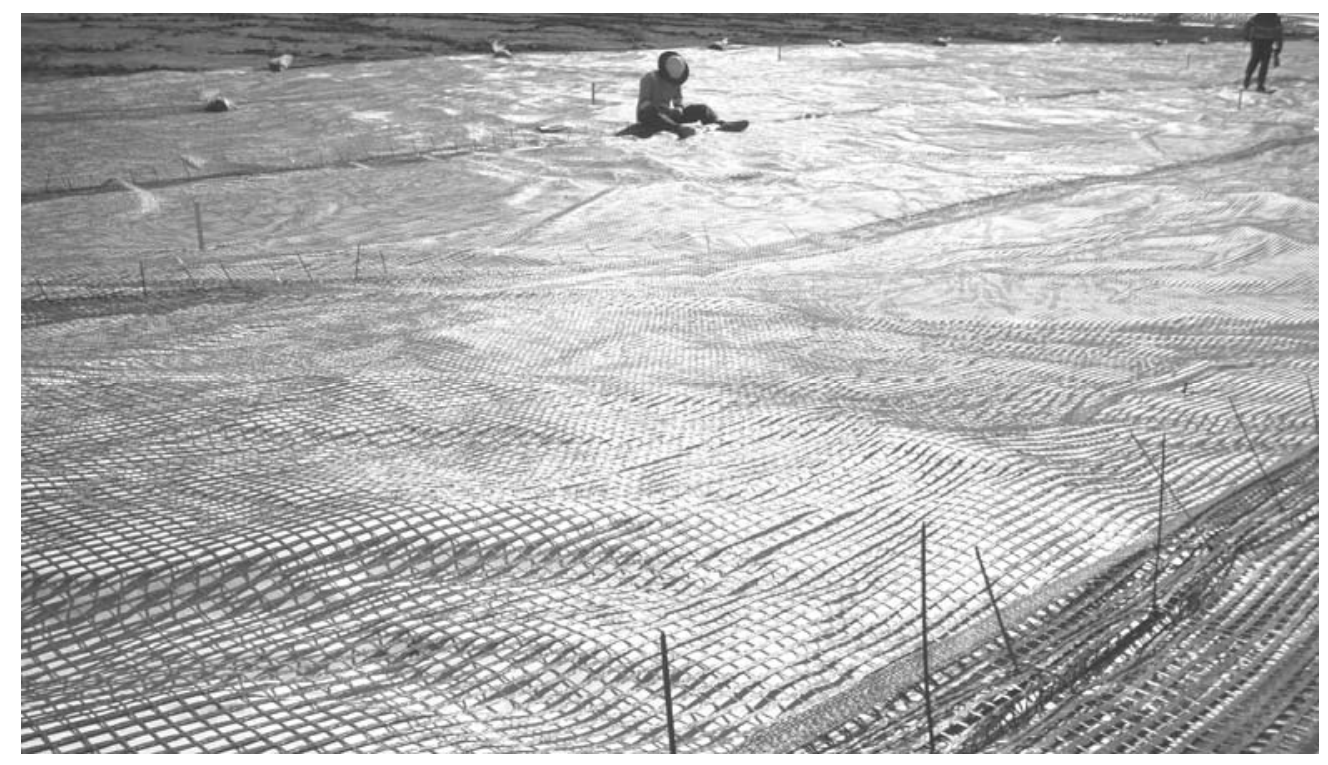

Figure 16 Photograph of stitching of geogrid seams with cable ties 


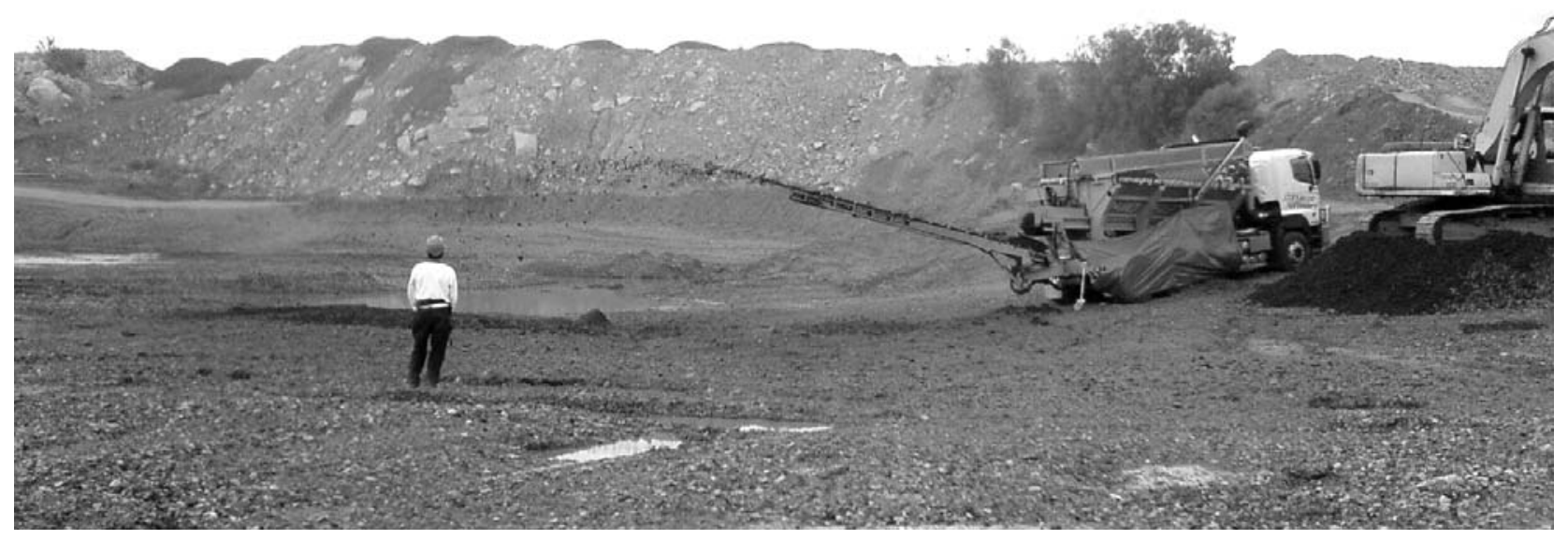

Figure 17 Photograph of slinger conveyor truck placing infill between fingers

\section{Acknowledgements}

ATC Williams wishes to thank Peabody Energy Australia for their support, particularly Michael Alexander.

\section{References}

Broms, B. (1987) Stabilization of Very Soft Clay using Geofabric, Geosynthetics and Geomembranes, Vol. 5, pp. $17-28$.

Hashim, A. and Murphy, S.D. (1994) Capping of Sediment Deposition Pits at Albert Park Lake, Melbourne, Australia, Journal of the Australian Geomechanics Society, Vol. 25, pp. 50-53. 
